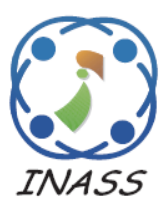

\title{
Enhanced Teacher Learning Based Optimization on Organic Rankine Cycle in Shell and Tube Heat Exchanger
}

\author{
Tallapureddy Subba Reddy ${ }^{1 *}$ \\ Erappa Rajj Babu ${ }^{1}$ \\ Thimmasandra Venkataswamy Sreerama Reddy ${ }^{1}$ \\ Hosur Nanji Reddy Reddappa ${ }^{1}$ \\ ${ }^{1}$ Department of Mechanical Engineering, Bangalore Institute of Technology, Bengaluru 560004, India \\ * Corresponding author's Email: phdsubbareddy@gmail.com
}

\begin{abstract}
Organic Rankine Cycle (ORC) fluids are applied in Shell and Tube Heat Exchanger for waste heat recovery to increase its efficiency. Various methods have been applied in the ORC in shell and tube heat exchanger, which has the limitation of low efficiency in optimization. In this research, Enhanced Teacher Learning Based Optimization (ETLBO) method has been proposed to increase the efficiency of the ORC in shell and tube heat exchanger. The Michalewicz was applied to the optimization method to provide global optimum and escape from the local optima. The E-TLBO method improves the convergence of the optimization and provides the effective performance in finding solution. The E-TLBO method has the advantages of two parameters such as population size and the number of iterations requires to set the value for optimization. The Shell and tube heat exchanger model has been developed to evaluate the performance of the optimization. The performance of E-TLBO is evaluated in four fluids namely R245fa, R134a, R290, and R600a in ORC analysis. The proposed E-TLBO method is compared with existing methods of BellDelaware and Kinetic Gas Molecule Optimization (KGMO) method. This analysis showed that R245fa fluid has a higher mass flow rate compared to other fluids. The proposed E-TLBO method has an enhancement factor of 3.14 and the existing KGMO has a 1.88 enhancement factor in R245fa fluid.
\end{abstract}

Keywords: Kinetic gas molecule optimization, Organic rankine cycle, R245fa, Shell and tube heat exchanger, Teacher learning based optimization.

\section{Introduction}

Heat exchangers are highly used in industries like oil refining, process industries and power plants for power generation. Among the various types of heat exchangers, the Shell and Tube Heat Exchangers (STHE) and Plate Heat Exchanger (PHE) are widely used in common devices like STHE. Therefore, it is important to improve the efficiency of the heat exchanger device using the design optimization technique. The tube and baffles configuration and their arrangement have a significant impact on the performance of this kind of heat exchanger [1]. In industry, heat exchangers are highly used for the heating and cooling process. The Operation of the heat exchanger is to transfer between the two fluids, as the conditions vary in different temperatures [2]. Generally, the exchangers are constructed with circular tubes with a highly flexible design in the core geometry and also the geometry which has changed in various length of tube diameter and arrangement. Many researchers have applied various optimization methods to improve heat exchanger performance. The ORC fluid is used in the exchanger for the lowtemperature heat source to make use of its energy. The Organic fluid of physical parameters are varied from the water, the structure of the steam boiler, and has different organic fluid evaporator [3-5].

Statistical analysis shows that more than half of the total heat exchangers in the industries tend to consists of low-grade waste heat. However, the conventional methods are not effective to convert the low-medium temperature heat to generate electrical power [6]. Organic Rankine cycle (ORC) is widely used in the energy that effectively utilizes due to high potential, low price, high efficiency, maintainability 
and simplicity compared with other Waste Heat Recovery (WHR) applications [7]. Many researchers are involved in alternative energy analysis especially waste energy and renewable energy. Various methods have been proposed to use energy from waste and renewable energy such as engine exhaust gases, biomass energy, solar energy, and geothermal energy. ORC can convert the thermal energy at low and medium temperature into mechanical or electricity [8]. Many researchers are relevant to ORC study in design optimization have been reported recently. The subjects involve applying second law analysis, system efficiency, operational condition optimization, thermo-economic analysis, model establishment, working fluid selection, and structure optimization $[9,10]$. In this research, the E-TLBO method has been applied to increase the efficiency of the exchanger with ORC. The Michalewicz method is applied in TLBO to find the effective solution in the search process. The E-TLBO method analysis the individual objective function to find global solution in the optimization. The E-TLBO method improves the convergence of the optimization and escape from local optima. The E-TLBO method performance is compared with the existing Bell-Delaware and KGMO methods.

The organization of this paper as follows; literature review is discussed in Section 2. The explanation of the proposed E-TLBO method is given in Section 3, the result and discussion are explained in Section 4. The conclusion of this proposed research is described in Section 5.

\section{Literature review}

The organic Rankine cycle method is used in shell and tube heat exchanger to increase thermal efficiency in a heat exchanger. Some existing methods were applied in the organic rankine cycle of shell and tube heat exchanger. Few types of research involved in the organic rankine cycle of shell and tube heat exchangers were reviewed in this section.

Milcheva [11] applied the adaptive BellDelaware method in shell and tube heat exchanger with a double-segmented baffle. The adaptive BellDelaware method was applied to some specific heat exchanger designs like leakage areas, an effective number of tubes and cross-flow area. The heat exchanger is simulated to analysis the performance of the proposed method with the design aspect. The simulation result showed that the adaptive BellDelaware method has a higher enhancement factor that compared to the existing method. The various design values were used to estimate the performance of the model. The R245fa fluid was used in the simulation to evaluate the model performance. An effective optimization method is required to improve the efficiency of the model.

Li [12] analyzed the optimal thermo-economic performance of the ORC in shell and tube heat exchanger. Three common heat exchanger designs and five hydrocarbon fluids were used to evaluate the performance of the heat exchanger model. This analysis showed that the arranged form of heat exchanger reduced the cost of the model. The system parameter, optimal working fluids, purchase cost of the exchanger had been optimized. The Optimal arranged form of the heat exchanger is based on the fluid that worked and heat source temperature. This analysis showed that the model increases the efficiency that reduced the cost of the model. The pressure value of the developed model is required to reduce by using an effective optimization method.

Tallapureddy and Thimmasandra, [13] proposed Kinetic Gas Molecule Optimization (KGMO) for optimal parameter settings for the STHE to improve the performance. The double-segmented baffle design was used to test the performance of the KGMO model in optimization. The two ORC fluids such as R245fa and R134a were used to test the performance of the developed method. This method has the limitation of not adaptively improve the design parameters in the model.

Tallapureddy and Thimmasandra, [14] applied the modified KGMO model to find the optimal parameters to improve the performance of the model. The feedback learning was applied in the KGMO to adaptively update the performance of the model. The two ORC fluids such as R245fa and R134a were used to test the performance of the modified KGMO method. The optimization method is trap into local optima that affects degrades the performance of the method.

Tallapureddy and Thimmasandra, [15] applied the modified KGMO model in a double segmented baffle design with the ORC fluids such as R290 and R600a. The feedback learning in the KGMO method is adaptively update the optimization of the model to improve the performance. The simulation shows that modified KGMO method has higher performance compared to the existing method. The modified KGMO method has the limitation of trap into local optima and poor convergence in the search.

Zhang [16] analyzed the ORC of a finned-tube heat exchanger, shell and tube heat exchanger and plate heat exchanger for thermo-economic performance. The thermo-economic model is developed and evaluated on four configurations of the ORC analysis. The designed parameter of the heat exchanger is analyzed to evaluate the performance of 
the heat exchanger. This analysis showed that the two configurations of the ORC model have higher performance than the other two configurations. The analysis of ORF-FS configuration has a costeffective performance. The optimal design value is analyzed and provided the effective performance of the model. The efficiency of the optimization method is required to improve the thermal performance and decrease the pressure.

Erdogan [17] analyzed the ORC shell and tube heat exchanger design that combined the parabolic trough solar collectors (PTSCs). The logarithmic mean temperature of a different method of thermal model of shell and tube heat exchanger has been developed. The designed key aspect of the heat exchanger is analyzed based on the heat transfer surface area of a heat exchanger. The fluid of R245fa and R600 was used to evaluate the performance of the model. This analysis showed the baffle space has an important parameter that affects the model parameter. The heat transfer area is another important parameter that affects the performance of the model. The optimization is required to applied and to detect the optimal design parameter of the model.

$\mathrm{Li}$ [18] analyzed the thermo-economic performance and Heat Exchanger Pressure Drop (HEPD) of the ORC shell and tube heat exchanger. An iterative method was applied to analyze the thermo-economic performance of the model and the HEPD on ORC was compared with an existing method to analyze the efficiency of the model. This analysis showed that the HEPD model affects the economy where the thermal performances were compared to existing methods. The analysis showed that the heat exchanger was designed with a small cross-section to increase efficiency. The optimized thermo-economic performance was provided with the efficient performance that compared to the conventional design. An effective optimization method is needed to be applied to increases the performance.

\section{Proposed method}

Organic Rankine Cycle is applied in shell and tube heat exchanger which utilizes the small heat in the exchanger to increases the efficiency. The existing methods have the limitation of low efficiency in the optimization. In this research, the ETLBO method has been applied to increase the efficiency of the heat exchanger. The mathematical model of the shell and tube heat exchanger with ORC is developed to evaluate the efficiency of the model. Four fluids such as R245fa, R134a, R290, and R600a were used to evaluate the performance of the heat

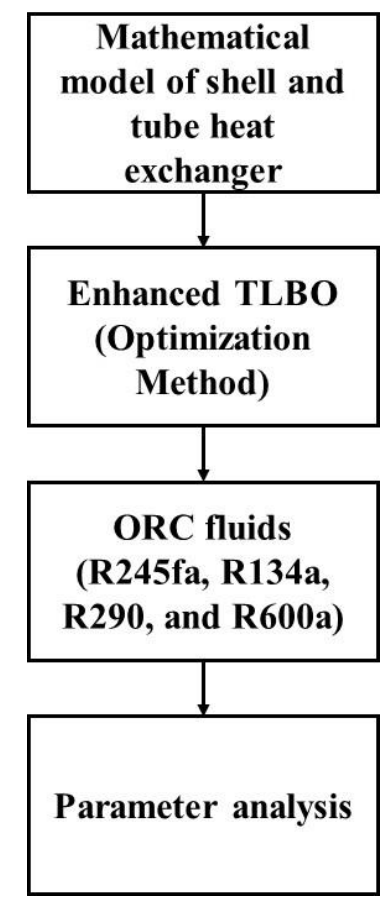

Figure. 1 The block diagram of Teacher Learning Based Optimization in ORC

exchanger. The block diagram of Teacher Learning Based Optimization in ORC is presented Fig. 1.

\subsection{Heat exchanger model}

The simulation of ORC preheater zone is described and several zone of heat exchanger is described [11]. The tube, the separator, the hot fluid and the cold fluid are described for each zone. For each zone, ordinary differential equations with time derivatives applying the finite volume method is measured. TIL 2.0 library cell models are used to develop the entire heat exchanger and this library is used to adjusted based on geometry parameters, pressure drop information, and heat transfer. The specific heat exchanger problem represents by the suitable interfaced cells. Each cell model represents the wall sections or control volumes and consist of discretized equations for the energy balances and material. Three cell types are considered for the preheater simulation:

- Refrigerant cells (liquid and vapour present, and phase change considered) for fluid in shell side (R245fa)

- Liquid cells (liquid phase present, no phase change) for geothermal fluid in the tube and

- Wall cells for the separator and the tube walls.

Separator divide the heat exchanger into two sub models such as Heat Exchanger 1 (HE1) and Heat Exchanger 2 (HE2) are divided from heat exchanger model. The upper pass of heat exchanger is represented in HE1 and bottom pass of heat 
exchanger is represented in HE2. The HE1 allows geothermal fluid enter the preheater and HE2 allows $\mathrm{R} 245 \mathrm{fa}$ enter the preheater.

\subsubsection{Tube-side design}

For a fully developed turbulent flow and considered load conditions, the tube Reynolds number $(\operatorname{ReD})$ is set as higher than $10^{4}$ value. Heat transfer correlation for this flow regime in tube-side is selected based on research [11], as in Eq. (1).

$$
\begin{gathered}
N u_{t}=\left(\frac{\left(\frac{f}{8}\right) R e_{D} \operatorname{Pr}}{1+12.7\left(\frac{f}{8}\right)^{\frac{1}{2}}\left(\operatorname{Pr}^{\frac{2}{3}}-1\right)}\right) \\
\left\{1+\left(\frac{d_{i n}}{L}\right)^{\frac{2}{3}}\right\}\left(\frac{P r_{t}}{P r_{t w}}\right)^{0.11}, R e_{D} \geq 10^{4}
\end{gathered}
$$

The research [11] is followed for measuring the friction factor $f$ in Eq. (1), as shown in Eq. (2).

$$
f=\left(1.8 \log _{10} R e_{D}-1.5\right)^{-2}, 10^{4} \leq R e_{D} \leq 10^{6}
$$

\subsubsection{Shell-side design}

The Bell-Delaware method of Taborek version is applied for measuring the average HTC in shell-side $h_{s}$, as given in Eq. (3). The correlation factors are product with the ideal HTC to measure the shell-side HTC.

$$
h_{s}=J_{c} J_{l} J_{r} J_{b} J_{s} h_{i}
$$

Various effects are considered into the account in this method that decrease the ideal HTC $h_{i}$ on the cross flow of the tube bank. Ideal cross regime deviation is considered in the account to form several correction factors $\left(J_{c}, J_{l}, J_{r}, J_{b}, J_{s}\right)$.

The flow across the ideal tube bank of HTC is used to determine the ideal HTC $h_{i}$.

$$
h_{i}=\frac{j_{i} C_{p s} G_{s}\left(\Phi_{s}\right)^{n}}{P r_{s}^{\frac{2}{3}}}
$$

\subsubsection{Shell side crossflow area}

The heat exchanger model is symmetry and the flow in the window of left and right is assumed equal. The flow areas $S_{m, l}$ and $S_{m, r}$ are the addition of the right and left flow and this is measure the cross flow area of shell side $S_{m}$. The cross flow area of shell side is measured in Eq. (5).

$$
S_{m}=S_{m, l}+S_{m, r}=L_{b c}\left(b x-N_{t c f} d\right) .2
$$

The overlapping region in both tube rows of the $N_{t c f}$ tube number amount is set as 11 in the analysis. To measure the cross flow area in shell side $S_{m, l}$ or $S_{m, r}$ in the model, the cross flow region width and the central baffle spacing $L_{b c}$ is multiplied. To measure the latter, the total tubes width $N_{t c f} \times d$ is subtracted from the whole width $b_{x}$ in the model. The product of shell side cross flow area is doubled to measure the shell side cross flow area $S_{m}$.

\subsubsection{Tube row number}

To measure the total effective cross flow in tube row $N_{t c c}$, the tube row $N_{t c c, l}$ and $N_{t c c, r}$ are added, as given in Eq. (6).

$$
N_{t c c}=N_{t c c, l}+N_{t c c, r}
$$

The cross flow in tube row $N_{t c c}$ is set as 4 and the number of tube rows $N_{t c c, l}$ and $N_{t c c, r}$ amount both to 2 in the analysis. To measure the tube number in wing-window $N_{t w, w}$, the total numbers of the right and left wing windows $N_{t w, r}$ and $N_{t w, l}$ are added, as given in Eq. (7).

$$
N_{t w, w}=N_{t w, l}+N_{t w, r}
$$

\subsubsection{Adaption of input parameters}

The central baffle and wing baffles have various geometrical measures like number of baffle window tubes. To measure average tube in window, the tube number in right and left wind window are considered, as given in Eq. (8). To measure the tube fraction $F_{w}$ in the baffle window, the window average tube number and total tube number $N_{t}$ is divided, as in Eqs. (8) and (9). The average number of tubes in the model is measured based on the wing window tubes and central wing window tubes.

$$
\begin{gathered}
N_{t w}^{a v e r}=0.5\left(N_{t w, w}+N_{t w, c}\right) \\
F_{w}=\frac{N_{t w}^{a v e r}}{N_{t}}
\end{gathered}
$$

Similarly, tube to baffle leakage areas and shell to baffle is given in Eq. (10).

$$
S_{s b}^{a v e r}=0.5\left(S_{s b, w b, l}+S_{s b, w b, r}+S_{t b, c b}\right)
$$

The separate leakage areas are applied to build to the average leakage area to calculate the actual heat exchanger design. 


\subsection{Enhanced teacher learning based optimization}

The TLBO method is inspired from teacher educate the student process. This method nondominated solutions are the learning capacity of the teacher or student [19-20] and the population denotes the students.

The teaching-learning process is used in the method in a classroom. Assume two teachers $T_{1}$ and $T_{2}$ teaching a same concept to some students having equal learning power in two different classes. In this method, the students are denoted as learners.

After teacher taught the subject and all the learners may not gain the equal knowledge. Learners consists of unequal knowledge and to increases the knowledge, the learners will interact among them consider each-others knowledge in a particular subject. Learners process is continuing until stopping criteria or improved knowledge levels. The learners have the various knowledge of each subject taught by the teacher in the stopping criteria. The ParetoOptimal front solution is provided by learner and mean knowledge level is applied to improve the learner capacity.

\subsubsection{Teacher phase}

The teacher attempts to teach the most of knowledge to all the learners in this phase. The objective function values are decided based on the individuals learning capability [21]. The teacher attempt to improve the mean knowledge the class level and improve all the learners up to his knowledge level.

Consider the teacher $T_{i}$ and the mean $M_{i}$ at any iteration $i$. The $T_{i}$ attempt to improve the mean $M_{i}$ to its own level and the $T_{i}$ designated new mean is denoted as $M_{\text {new }}$. Based on the new mean and the existing, the solution are updated, given in Eq. (11).

$$
\text { Mean Difference }_{i}=r_{i}\left(M_{\text {new }}-M_{i}\right)
$$

Where a random number between 0 and 1 is denoted as $r_{i}$.

Modified existing solutions are follows in Eq. (12).

$$
X_{\text {new }, i}=X_{\text {old }, i}+\text { Difference } \text { Mean }_{i}
$$

\subsubsection{Learner phase}

Two different means: one is teacher input and other is interaction between the learners [22]. In the manner of group discussions, formal communications, and presentation, learners interact among them. If learner learn something new, the information is shared with other learners. Learner process is expressed as:

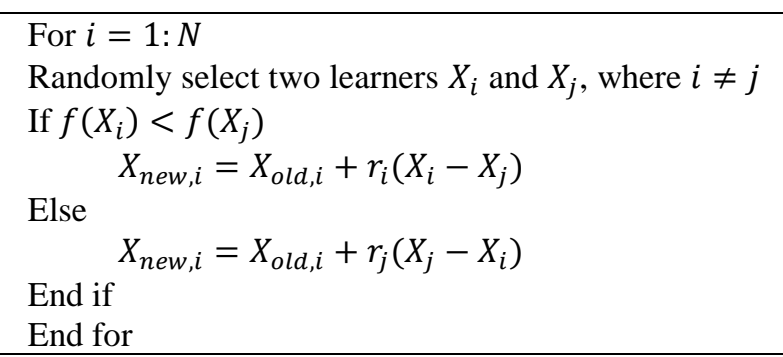

Michalewicz is applied in the TLBO to improve the global solution, as given in Eq. (13).

$$
f(x)=-\sum_{i=1}^{d} \sin \left(X_{i, j}\right) \operatorname{Sin}^{2 m}\left(\frac{i x_{i}^{2}}{\pi}\right)
$$

Where $f\left(X_{i}\right)$ and $f\left(X_{j}\right)$ are the objective function values of individuals $X_{i}$ and $X_{j}$ value

Accept $X_{\text {new }}$ if it is give better objective function

\section{Results and discussion}

Organic Rankine Cycle(ORC) is applied in Shell and tube heat exchanger to use small heat in the exchanger for heat transfer. Various existing methods have been applied in ORC in the heat exchanger to improve the thermal performance and reduce the pressure. Existing methods have the limitation of low optimization performance in the ORC of a heat exchanger. In this research, the E-TLBO method has been applied in ORC of heat exchanger in four kinds of fluid. The fluids such as R245fa, R134a, R290, and R600a were used to evaluate the performance of the E-TLBO method. The proposed E-TLBO method is compared with existing methods like the BellDelaware method and the KGMO method. The model of shell and tube heat exchanger and fluid were implemented in the system of Intel i7 processor and $16 \mathrm{~GB}$ of RAM. Various parameters of exchanger like enhancement factor, temperature, pressure, etc., were analyzed in the method. The HTCs and Reynolds number of shell and tube sides is given in Table 1. A detailed description of the performance of the proposed E-TLBO and existing KGMO method results were discussed in this research. The Enhancement factor $J_{x}$, outlet temperature (out-T), inlet temperature (in-T), inlet pressure (in-P), outlet pressure (out-P), Geothermal water inlet temperature (GW-in-T), Mass Flow (MF), Geothermal water outlet pressure (GW-out-P), Thermal water mass flow (TWMF), Relative deviation of fluid outlet temperature (fluid RD-out-T), Relative deviation 
Table 1. Shell and tube side of HTCs and reynolds number

\begin{tabular}{|c|c|c|c|c|c|c|c|c|c|}
\hline & $\alpha_{s s, \min }$ & $\alpha_{s s, \max }$ & $\boldsymbol{R} \boldsymbol{e}_{s, \min }$ & $R e_{s, \max }$ & $\alpha_{t s, \min }$ & $\alpha_{t s, \max }$ & $\boldsymbol{R} \boldsymbol{e}_{t, \min }$ & $R e_{t, \max }$ & $\frac{\alpha_{t s, \text { max }}}{\alpha_{s s, \text { max }}}$ \\
\hline Unit & $\left(\mathrm{W} / \mathrm{m}^{2} \mathrm{~K}\right)$ & $\left(\mathrm{W} / \mathrm{m}^{2} \mathrm{~K}\right)$ & - & - & $\left(\mathrm{W} / \mathrm{m}^{2} \mathrm{~K}\right)$ & $\left(\mathrm{W} / \mathrm{m}^{2} \mathrm{~K}\right)$ & - & - & - \\
\hline R245fa & 1204 & 1219 & 63743 & 73544 & 14058 & 14245 & 113728 & 118501 & 11.68 \\
\hline $\mathrm{R} 134 \mathrm{a}$ & 1162 & 1126 & 57212 & 68126 & 12021 & 12165 & 10165 & 101311 & 10.67 \\
\hline R290 & 1016 & 1021 & 5412 & 65126 & 11312 & 11014 & 9046 & 9111 & 10.78 \\
\hline R600a & 981 & 987 & 5216 & 64165 & 10213 & 10361 & 9021 & 9100 & 10.49 \\
\hline
\end{tabular}

Table 2. The proposed TLBO performance analysis on R245fa fluid

\begin{tabular}{|c|c|c|c|c|c|c|c|}
\hline Factors & Units & $\begin{array}{c}\text { Bell-Delaware } \\
\text { method [11] }\end{array}$ & $\begin{array}{c}\text { Parametric } \\
\text { optimization } \\
{[\mathbf{1 2}]}\end{array}$ & $\begin{array}{c}\text { KGMO } \\
{[\mathbf{1 3}]}\end{array}$ & $\begin{array}{c}\text { Modified } \\
\text { KGMO } \\
{[\mathbf{1 5}]}\end{array}$ & TLBO & E-TLBO \\
\hline$J_{x}$ & - & 1.51 & 1.65 & 1.88 & 2.8063 & 3.14 & 3.42 \\
\hline in-T & ${ }^{\circ} \mathrm{C}$ & 19.9 & 19.9 & 19.90 & 19.900 & 19.900 & 19.9 \\
\hline out-T & ${ }^{\circ} \mathrm{C}$ & 59.34 & 62.3 & 64.52 & 64.2804 & 65.17 & 65.32 \\
\hline in-P & bar & 5.48 & 5.48 & 5.48 & 5.4800 & 5.48 & 5.48 \\
\hline out-P & bar & 5.18 & 5.12 & 4.38 & 4.3800 & 4.27 & 4.21 \\
\hline MF & kg/s & 85.55 & 86.3 & 88.33 & 88.3333 & 89.21 & 89.72 \\
\hline GW-in-T & ${ }^{\circ} \mathrm{C}$ & 66.64 & 66.64 & 66.64 & 66.6400 & 66.64 & 66.64 \\
\hline GW-out-T & ${ }^{\circ} \mathrm{C}$ & 47.77 & 48.2 & 52.14 & 51.9004 & 53.31 & 53.61 \\
\hline GW-in-P & bar & 15 & 15 & 15 & 15 & 15 & 15 \\
\hline GW-out-P & bar & 15 & 12 & 4.38 & 4.3800 & 4.38 & 4.38 \\
\hline TWMF & $\mathrm{kg} / \mathrm{s}$ & 58.1 & 60.4 & 61.18 & 60.9404 & 60.9404 & 62.05 \\
\hline fluid RD-out-T & $\%$ & 0.38 & 0.38 & 0.32 & 0.3214 & 0.32 & 0.32 \\
\hline RD-out-T & $\%$ & -0.19 & -0.19 & -0.14 & -0.1400 & -0.14 & -0.14 \\
\hline
\end{tabular}

Table 3. The proposed E-TLBO performance on R134a fluid

\begin{tabular}{|c|c|c|c|c|c|c|c|}
\hline Factors & Units & $\begin{array}{c}\text { Bell-Delaware } \\
\text { method [11] }\end{array}$ & $\begin{array}{c}\text { Parametric } \\
\text { optimization [12] }\end{array}$ & $\begin{array}{c}\text { KGMO } \\
{[\mathbf{1 3}]}\end{array}$ & $\begin{array}{c}\text { Modified } \\
\text { KGMO } \\
{[\mathbf{1 5}]}\end{array}$ & TLBO & E-TLBO \\
\hline$J_{x}$ & - & 1.14 & 1.21 & 1.2329 & 1.9346 & 2.03 & 2.21 \\
\hline in-T & ${ }^{\circ} \mathrm{C}$ & 19.9 & 19.9 & 19.9000 & 19.9000 & 19.90 & 19.9 \\
\hline out-T & ${ }^{\circ} \mathrm{C}$ & 40.21 & 41.12 & 42.1741 & 44.3508 & 45.42 & 46.21 \\
\hline in-P & bar & 5.48 & 5.48 & 5.4800 & 5.4800 & 5.48 & 5.48 \\
\hline out-P & bar & 6.58 & 6.58 & 6.5800 & 6.5800 & 6.58 & 6.58 \\
\hline MF & $\mathrm{kg} / \mathrm{s}$ & 65.2 & 65.7 & 67.0000 & 67.0000 & 69.00 & 70 \\
\hline GW-in-T & ${ }^{\circ} \mathrm{C}$ & 66.64 & 66.64 & 66.6400 & 66.6400 & 66.64 & 66.64 \\
\hline GW-out-T & ${ }^{\circ} \mathrm{C}$ & 24.21 & 26.34 & 27.5941 & 29.7708 & 30.02 & 30.5 \\
\hline GW-in-P & $\mathrm{bar}$ & 15 & 15 & 15.0000 & 15.0000 & 15.00 & 15 \\
\hline GW-out-P & $\mathrm{bar}$ & 17.2 & 17.2 & 17.3000 & 17.3000 & 17.02 & 17.02 \\
\hline TWMF & $\mathrm{kg} / \mathrm{s}$ & 34.6 & 38.1 & 38.3141 & 40.4908 & 41.06 & 41.15 \\
\hline fluid RD-out-T & $\%$ & 0.4032 & 0.4032 & 0.4032 & 0.4032 & 0.4032 & 0.4032 \\
\hline RD-out-T & $\%$ & -0.26 & -0.26 & -0.2600 & -0.2600 & -0.2600 & -0.2600 \\
\hline
\end{tabular}

geothermal fluid outlet temperature (RD-out-T) are analysed in the tables.

\subsection{Analysis using R245fa fluid}

The proposed E-TLBO performance is analyzed in the model by comparing with the existing methods, as shown in Table 2 . This analysis showed that the ETLBO method has higher performance compared to existing methods like Bell-Delaware [11] and KGMO. The E-TLBO method has the advantage of apply Michalewicz method in TLBO method to improve the convergence and provide global solution. The Michalewicz provides the solution based on the global solution to improve the exploitation of the best solution. By analyzing E-TLBO that enhances the factor of 3.42 with the existing KGMO method has a 1.88 enhancement factor. The proposed E-TLBO method in R245fa fluid has an outlet temperature of $65.32^{\circ} \mathrm{C}$, outlet pressure of 4.21 bar and the mass flow rate of $89.72 \mathrm{~kg} / \mathrm{s}$. The analysis showed that the E-TLBO method has a higher outlet temperature with mass flow rate and lower outlet pressure compared to existing methods such as KGMO, modified KGMO 
Table 4. The proposed E-TLBO performance on R290 fluid

\begin{tabular}{|c|c|c|c|c|c|c|c|}
\hline Factors & Units & $\begin{array}{c}\text { Bell- } \\
\text { Delaware } \\
\text { method } \\
{[\mathbf{1 1}]}\end{array}$ & $\begin{array}{c}\text { Parametric } \\
\text { optimization } \\
{[\mathbf{1 2}]}\end{array}$ & $\begin{array}{c}\text { KGMO } \\
{[\mathbf{1 3}]}\end{array}$ & $\begin{array}{c}\text { Modified } \\
\text { KGMO } \\
{[\mathbf{1 5}]}\end{array}$ & TLBO & $\begin{array}{c}\text { E- } \\
\text { TLBO }\end{array}$ \\
\hline$J_{x}$ & - & 1.01 & 1.01 & 1.02 & 1.72 & 2.04 & 2.16 \\
\hline in-T & ${ }^{\circ} \mathrm{C}$ & 17.08 & 17.08 & 17.08 & 17.08 & 17.08 & 17.08 \\
\hline out-T & ${ }^{\circ} \mathrm{C}$ & 33.7 & 35.2 & 36.14 & 37.61 & 41.31 & 42.17 \\
\hline in-P & Bar & 5.10 & 5.10 & 5.10 & 5.10 & 5.10 & 5.10 \\
\hline out-P & Bar & 5.09 & 5.03 & 5.07 & 4.82 & 4.42 & 4.41 \\
\hline MF & $\mathrm{kg} / \mathrm{s}$ & 55.2 & 55.6 & 57.01 & 57.21 & 58.00 & 59.11 \\
\hline GW-in-T & ${ }^{\circ} \mathrm{C}$ & 58.48 & 58.48 & 58.48 & 58.48 & 58.48 & 58.48 \\
\hline GW-out-T & ${ }^{\circ} \mathrm{C}$ & 22.16 & 22.14 & 22.12 & 22.17 & 23.12 & 23.15 \\
\hline GW-in-P & $\mathrm{bar}$ & 15 & 15 & 15.00 & 15.00 & 15.00 & 15 \\
\hline GW-out-P & $\mathrm{bar}$ & 12.35 & 12.34 & 12.30 & 12.21 & 12.10 & 12.07 \\
\hline TWMF & $\mathrm{kg} / \mathrm{s}$ & 30.24 & 31.26 & 32.31 & 32.51 & 34.49 & 34.52 \\
\hline fluid RD-out-T & $\%$ & 0.3032 & 0.3032 & 0.3032 & 0.3032 & 0.3032 & 0.3032 \\
\hline RD-out-T & $\%$ & -0.2100 & -0.2100 & -0.2100 & -0.2100 & -0.2100 & -0.2100 \\
\hline
\end{tabular}

Table 5. The proposed E-TLBO method performance on R600a fluid

\begin{tabular}{|c|c|c|c|c|c|c|c|}
\hline Factors & Units & $\begin{array}{c}\text { Bell- } \\
\text { Delaware } \\
\text { method } \\
{[\mathbf{1 1}]}\end{array}$ & $\begin{array}{c}\text { Parametric } \\
\text { optimization } \\
{[\mathbf{1 2}]}\end{array}$ & $\begin{array}{c}\text { KGMO } \\
{[\mathbf{1 3}]}\end{array}$ & $\begin{array}{c}\text { Modified } \\
\text { KGMO } \\
{[\mathbf{1 5}]}\end{array}$ & TLBO & E-TLBO \\
\hline$J_{x}$ & - & 0.96 & 0.97 & 1.01 & 1.12 & 1.21 & 1.32 \\
\hline in-T & ${ }^{\circ} \mathrm{C}$ & 19.9 & 19.9 & 19.90 & 19.90 & 19.90 & 19.9 \\
\hline out-T & ${ }^{\circ} \mathrm{C}$ & 30.12 & 31.15 & 32.10 & 33.52 & 34.31 & 35.43 \\
\hline in-P & bar & 4.1 & 4.1 & 4.10 & 4.10 & 4.10 & 4.1 \\
\hline out-P & bar & 5.21 & 5.21 & 5.21 & 5.21 & 5.21 & 5.21 \\
\hline MF & $\mathrm{kg} / \mathrm{s}$ & 55.12 & 55.72 & 56.00 & 56.20 & 57.00 & 58.21 \\
\hline GW-in-T & ${ }^{\circ} \mathrm{C}$ & 58.67 & 58.67 & 58.67 & 58.67 & 58.67 & 58.67 \\
\hline GW-out-T & ${ }^{\circ} \mathrm{C}$ & 20.4 & 20.6 & 21.10 & 22.16 & 23.72 & 23.81 \\
\hline GW-in-P & $\mathrm{bar}$ & 12 & 12 & 12.00 & 12.00 & 12.00 & 12 \\
\hline GW-out-P & $\mathrm{bar}$ & 16.2 & 16.2 & 16.2 & 16.2 & 16.2 & 16.2 \\
\hline TWMF & $\mathrm{kg} / \mathrm{s}$ & 24.3 & 24.6 & 26.32 & 27.12 & 28.38 & 28.76 \\
\hline fluid RD-out-T & $\%$ & 0.32 & 0.32 & 0.32 & 0.32 & 0.32 & 0.32 \\
\hline RD-out-T & $\%$ & -0.28 & -0.28 & -0.28 & -0.28 & -0.28 & -0.28 \\
\hline
\end{tabular}

and Bell-Delaware. E-TLBO method has the advantage of requiring only two parameters to perform optimization such as population and number of iteration.

\subsection{Analysis using R134a fluid}

The proposed E-TLBO method has been applied in the R134a fluid and compared with the existing KGMO method, as shown in Table 3. The analysis showed that the E-TLBO method has a higher enhancement factor compared to the existing KGMO method. The E-TLBO method has an enhancement factor of 2.21 and the existing KGMO method has a 1.2329 enhancement factor. The proposed E-TLBO method increases the mass flow rate of $70 \mathrm{~kg} / \mathrm{s}$ and the existing KGMO method has a $67 \mathrm{~kg} / \mathrm{s}$ mass flow rate. The proposed E-TLBO has a higher mass flow rate and lower pressure compared to the existing
KGMO method. The proposed E-TLBO method has the advantage of utilizing only two parameters for optimization such as population size and a number of iteration. The proposed E-TLBO method has the advantage of good convergence based on Michalewicz method to improve the efficiency of the solution.

\subsection{Analysis using R290 fluid}

The proposed E-TLBO method is applied in R290 fluid and compared with the existing KGMO method, as shown in Table 4. This analysis showed that the proposed E-TLBO method has a higher enhancement factor compared to the existing KGMO method. The proposed E-TLBO method has a 2.16 enhancement factor compared to the existing KGMO has a 1.02 enhancement factor. The proposed E-TLBO method has lower pressure compared to the existing KGMO 
method. The proposed E-TLBO method has a mass flow rate of $59.11 \mathrm{~kg} / \mathrm{s}$ and the existing KGMO method has $58.48 \mathrm{~kg} / \mathrm{s}$ in R290 fluid in ORC. The proposed E-TLBO method has the advantage of utilizing only two parameters to set such as population size and a number of iterations.

\subsection{Analysis using R600a fluid}

The proposed E-TLBO method is analyzed in the R600a fluid by comparing it with the existing KGMO method, as shown in Table 5. This analysis showed that the proposed E-TLBO method has a higher enhancement factor compared to the existing KGMO method. The proposed E-TLBO method has an enhancement factor of 1.32 and the existing method has a 1.01 enhancement factor. The proposed ETLBO method has lower pressure compared to the existing KGMO method. The proposed E-TLBO method has a mass flow of $58.21 \mathrm{~kg} / \mathrm{s}$ and the existing KGMO method has a $56 \mathrm{~kg} / \mathrm{s}$ mass flow. The proposed E-TLBO method has the advantage of utilizing only two parameters to set such as population size and a number of iterations. The proposed E-TLBO method has the advantage of improve the global solution and convergence based on Michalewicz method. The proposed E-TLBO method has higher efficiency compared to the existing Bell-Delaware and KGMO method. The proposed E-TLBO method has lower pressure and higher mass flow in four kinds of fluids.

\section{Conclusion}

Organic Rankine Cycle (ORC) fluids are used in Shell and Tube Heat Exchanger for waste heat recovery to increase its efficiency. The existing methods in ORC in shell and tube heat exchanger have low efficiency in optimization. In this research, the E-TLBO method is proposed in ORC to increases the efficiency of the exchanger. The Michalewicz is applied in the TLBO to improve the global solution of the method. This improve the convergence of the method and escape from the local optima in the search process. The E-TLBO method has the advantage in two parameters like population size and the number of iterations required to set the value for optimization. The mathematical model of shell and tube heat exchanger with fluids is developed to evaluate the E-TLBO method. The four fluids such as R245fa, R134a, R290, and R600a were used to evaluate the performance of the E-TLBO and KGMO methods. The E-TLBO method provides the optimal design parameter to increases the efficiency of the exchanger model. This analysis showed that the proposed E-TLBO method has a higher mass flow rate and lower pressure compared to the existing BellDelaware and KGMO methods. The proposed ETLBO method has higher efficiency in four fluids in the analysis compared to the KGMO method. The analysis shows that the R245fa fluid has higher efficiency compared to the other three fluids. The proposed E-TLBO method improved the mass flow rate of the design that increases the thermal performance of the exchanger. The mass flow rate of E-TLBO design is the $89.72 \mathrm{~kg} / \mathrm{s}$ and existing Modified KGMO method has $88.33 \mathrm{~kg} / \mathrm{s}$. The analysis shows that the proposed E-TLBO method has an enhancement factor of 3.14 and the existing method has a 1.88 enhancement factor. The future work of this method involves developing the hybrid optimization method to improve the thermal performance in ORC.

\section{Nomenclature}

\begin{tabular}{|c|c|}
\hline$C$ & Specific heat capacity $(W /(K g K))$ \\
\hline$d$ & Tube outside diameter $(m)$ \\
\hline$f$ & Friction Factor \\
\hline$G$ & Mass velocity \\
\hline$h$ & Heat transfer coefficient \\
\hline$j$ & Colburn factor \\
\hline$J_{c}, J_{l}, J_{r}, J_{b}, J_{s}$ & Correlation factors \\
\hline$L$ & Spacing $(\mathrm{m})$ \\
\hline$N_{t c c}$ & $\begin{array}{l}\text { effective numbers of tube rows in cross } \\
\text { flow between baffle tips }\end{array}$ \\
\hline$N_{t c f}$ & Overlapping region \\
\hline$N_{t w}$ & Total number of tubes in wing window \\
\hline $\mathrm{Nu}$ & Nusselt Number \\
\hline $\operatorname{Pr}$ & Prandtl number \\
\hline$R e_{D}$ & Reynolds number \\
\hline$S_{m}$ & Shell side Cross flow area $\left(\mathrm{m}^{2}\right)$ \\
\hline$T_{1}$ and $T_{2}$ & Teachers \\
\hline$X_{i}$ and $X_{j}$ & Individual Objective functions \\
\hline$X_{\text {new }}$ & New Objective function \\
\hline \multicolumn{2}{|l|}{ Greek letters } \\
\hline$\Phi$ & Viscosity correction factor \\
\hline \multicolumn{2}{|l|}{ Subscript } \\
\hline$b$ & Baffle \\
\hline$c$ & Central \\
\hline in & Inlet \\
\hline$l$ & Left \\
\hline \multicolumn{2}{|l|}{$n$} \\
\hline$r$ & right \\
\hline$s$ & Shell \\
\hline$s S$ & Shell side \\
\hline$t$ & Tube \\
\hline$t s$ & Tube side \\
\hline
\end{tabular}




\section{Conflicts of Interest}

The authors declare no conflict of interest.

\section{Author Contributions}

The paper conceptualization, methodology, software, validation, formal analysis, investigation, resources, data curation, writing - original draft preparation, writing-review and editing, visualization, have been done by $1^{\text {st }}$ and $2^{\text {nd }}$ author. The supervision, and project administration, have been done by $3^{\text {rd }}$ and $4^{\text {th }}$ author.

\section{References}

[1] A. A. A. Arani and R. Moradi, "Shell and tube heat exchanger optimization using new baffle and tube configuration", Applied Thermal Engineering, Vol. 157, pp. 113736, 2019.

[2] M. H. Mohammadi, H. R. Abbasi, A. Yavarinasab, and H. Pourrahmani, "Thermal optimization of shell and tube heat exchanger using porous baffles", Applied Thermal Engineering, Vol. 170, p. 115005, 2020.

[3] H. Feng, L. Chen, Z. Wu, and Z. Xie, "Constructal design of a shell-and-tube heat exchanger for organic fluid evaporation process", International Journal of Heat and Mass Transfer, Vol. 131, pp. 750-756, 2019.

[4] E. M. El-Said and M. M. A. Al-Sood, "Shell and tube heat exchanger with new segmental baffles configurations: a comparative experimental investigation", Applied Thermal Engineering, Vol. 150, pp. 803-810, 2019.

[5] Z. Said, S. M. A. Rahman, M. E. H. Assad, and A. H. Alami, "Heat transfer enhancement and life cycle analysis of a Shell-and-Tube Heat Exchanger using stable $\mathrm{CuO} /$ water nanofluid", Sustainable Energy Technologies and Assessments, Vol. 31, pp. 306-317, 2019.

[6] C. Zhang, C. Liu, X. Xu, Q. Li, S. Wang, and X. Chen, "Effects of superheat and internal heat exchanger on thermo-economic performance of organic Rankine cycle based on fluid type and heat sources", Energy, Vol. 159, pp. 482-495, 2018.

[7] S. M. S. Mahmoudi, and A. R. Ghavimi, "Thermoeconomic analysis and multi objective optimization of a molten carbonate fuel cellsupercritical carbon dioxide-organic Rankin cycle integrated power system using liquefied natural gas as heat sink", Applied Thermal Engineering, Vol. 107, pp. 1219-1232, 2016.

[8] K. Hu, J. Zhu, W. Zhang, K. Liu, and X. Lu, "Effects of evaporator superheat on system operation stability of an organic Rankine cycle", Applied Thermal Engineering, Vol. 111, pp. 793-801, 2017.

[9] M. Linnemann, K. P. Priebe, G. Herres, C. Wolff, and J. Vrabec, "Design and test of a multi-coil helical evaporator for a high temperature organic Rankine cycle plant driven by biogas waste heat", Energy Conversion and Management, Vol. 195, pp. 1402-1414, 2019.

[10] H. Sun, J. Qin, T. C. Hung, H. Huang, P. Yan, and C. H. Lin, "Effect of flow losses in heat exchangers on the performance of organic Rankine cycle", Energy, Vol. 172, pp. 391-400, 2019.

[11] I. Milcheva, F. Heberle, and D. Brüggemann, "Modeling and simulation of a shell-and-tube heat exchanger for Organic Rankine Cycle systems with double-segmental baffles by adapting the Bell-Delaware method", Applied Thermal Engineering, Vol. 126, pp. 507-517, 2017.

[12] J. Li, Z. Yang, S. Hu, F. Yang, and Y. Duan, "Effects of shell-and-tube heat exchanger arranged forms on the thermo-economic performance of organic Rankine cycle systems using hydrocarbons", Energy Conversion and Management, Vol. 203, p. 112248, 2020.

[13] R. Tallapureddy and R. Thimmasandra, "Optimization of Shell and Tube Heat Exchanger Design in Organic Rankine Cycle System Using Kinetic Gas Molecule Optimization", International Journal of Intelligent Engineering and Systems, Vol. 12, No. 2, pp. 297-304, 2019.

[14] S. Tallapureddy and R. Thimmasandra, "Optimum Design of Shell and Tube Heat Exchangers using Modified Kinetic Gas Molecule Optimizer for the use of Low Temperature in Organic Rankine Cycles", International Journal of Engineering and Advanced Technology, Vol. 9, No. 3, pp. 19861993, 2020.

[15] T. S. Reddy, T. V. S. Reddy, E. R. Babu, and H. N. R. Reddappa, "Modified Kinetic Gas Molecule Optimization for four fluids of Organic Rankine Cycle in shell and tube heat exchanger", Materials Today: Proceedings, 2021.

[16] C. Zhang, C. Liu, S. Wang, X. Xu, and Q. Li, "Thermo-economic comparison of subcritical organic Rankine cycle based on different heat exchanger configurations", Energy, Vol. 123, pp. 728-741, 2017.

[17] A. Erdogan, C. O. Colpan, and D. M. Cakici, "Thermal design and analysis of a shell and tube 
heat exchanger integrating a geothermal based organic Rankine cycle and prabolic trough solar collectors", Renewable Energy, Vol. 109, pp. 372-391, 2017.

[18] X. Li, J. Song, G. Yu, Y. Liang, H. Tian, G. Shu, and C. N. Markides, "Organic Rankine cycle systems for engine waste-heat recovery: Heat exchanger design in space-constrained applications", Energy Conversion and Management, Vol. 199, pp. 111968, 2019.

[19] T. D. Varma and D. V. Kumar, "Multi-objective economic emission load dispatch using teacherlearning-based optimization technique", IFAC Proceedings, Vol. 47, No. 1, pp. 819-826, 2014.

[20] Y. Ma, X. Zhang, J. Song, and L. Chen, "A modified teaching-learning-based optimization algorithm for solving optimization problem", Knowledge-Based Systems, p. 106599, 2020.

[21] H. Dong, P. Wang, X. Yu, and B. Song, "Surrogate-assisted teaching-learning-based optimization for high-dimensional and computationally expensive problems", Applied Soft Computing, p. 106934, 2020.

[22] S. Li, W. Gong, L. Wang, X. Yan, and C. Hu, “A hybrid adaptive teaching-learning-based optimization and differential evolution for parameter identification of photovoltaic models", Energy Conversion and Management, Vol. 225, p. 113474, 2020. 